\title{
Local resection for placenta accreta spectrum: a conservative uterus sparing technique for anterior placenta accreta
}

\author{
Gülsüm Uysal๑, Nefise Tanrıdan Okçu๑, Eda Eskimez $\odot$, Esra Saygılı Yılmaz $\odot$ \\ Department of Obstetrics and Gynecology, University of Health Sciences, Adana Numune Training and Research Hospital, Adana, \\ Turkey
}

DOI: 10.18621 /eurj.382390

\begin{abstract}
Objectives: To evaluate and describe a surgical approach for uterine preservation and management of postpartum hemorrhage in placenta accreta spectrum (PAS).

Methods: We analyzed the data of patients who were diagnosed with placenta previa companied with PAS prenatally and subsequently performed cesarean section with local resection technique to manage postpartum hemorrhage and uterine preservation at our tertiary care center between January 2016 and August 2017. The technique includes the local resection of placental invasion site and suturing the new uterine edges without internal iliac artery ligation.

Results: The diagnosis of placenta accreta spectrum anterior in all 11 cases was confirmed intraoperatively. Only 1 case underwent hysterectomy in a second operation. Two of cases had bladder injury. The mean operative time was $99 \pm 30$ minutes. The mean received packed red blood cells was $2.3 \pm 1.0$ units. The mean length of postoperative hospital stay was $4.5 \pm 1.4$ days. There was no late complications regarding coagulopathy and infection. No maternal mortality was observed.

Conclusion: Local resection is an effective, safe and fertility preserving approach in selected patients with PAS.

Keywords: Placenta accreta spectrum, maternal morbidity, fetal outcome, fertility preservation, uterus preserving surgery, local resection
\end{abstract}

Received: January 22, 2018; Accepted: February 23, 2018; Published Online: April 11, 2018

$\mathbf{P}$ lacenta accreta spectrum (PAS) disorders, comprise the spectrum of adhesive plasental invasions formerly called placenta accreta, increta, percreta [1-3]. PAS refers to an abnormal implantation of anchoring placental vili to myometrium, uterine serosa or adjacent organs instead of staying limited to decidua [2, 3]. Major risk factors include placenta previa andprevious cesarean deliveries. Other risk factors are prioruterine scars (myomectomy, infertility treatments, cornual resection of ectopic pregnancy, hysteroscopic septum resections or removal of uterine adhesions), recurrent abortions, dilatation and curettage (D/C), smoking, advanced maternal age and parity [2-4]. PAS became an important life-threatening obstetric problem sincefrequency of ithas been risingconstantly in recent decades due to increasing rates of caesarean deliveries. Moreover, adherent placenta has been replacing withuterine atony as major cause of cesarean hysterectomy $[4,5]$.

Antenatal diagnosis, and planned preterm cesarean hysterectomy (between 34-35 weeks gestation) with the placenta left in situ is the recommended treatment

Address for correspondence: Nefise Tanridan Okçu, MD., University of Health Sciences, Adana Numune Training and Research Hospital, Obstetrics and Gynecology, 01170 Adana, Turkey 
in case of placenta accreta [6, 7]. It was also stated that surgical management should be individualized. Although planned preterm cesarean hysterectomy seems to be thesafest and most common treatment for placentaaccreta diagnosed before delivery, it is a skillfull, serious, and maybe a fertility loosing method [6]. Hence, gynecologist are looking for solutions for increasing cesarean delivery rates and medicolegal problems. Therefore, new methods of conservative management for fertility preservation and safe self esteem of women with placenta percretaare appealingin recent years [8, 9]. Conservative managementsinclude; leaving the placenta in situ, hysteroscopic resection of retained adherent placenta, partial en bloc resection with embolization, the Triple $P$ procedure which involves perioperative placental localization, pelvic devascularization, myometrial excision with non-seperated placenta and reconstruction of the uterine wall [10-15]. On the other hand uterine conservation and leaving the placenta in situ may be considered to mitigate the risk of hemorrhage or injury to other adjacent organs [2]. Uterine artery embolization, balloon occlusion, intravascular balloon catheter and embolization are the other techniques developed for PAS in literature [9]. However, there is no clear algorithm for adherent placenta management.

In this study, we evaluated the efficacy of local resection to preserve the uterus and aimed to share our clinical "local resection tecnique" results including maternal-fetal outcomes in patients with PAS.

\section{METHODS}

In present retrospective, descriptive study, data were collected from the medical records of patients who had been diagnosedwith placenta previa concomitant PAS (accreta, increta, percreta) between january 2016 and August 2017 in Department of Obstetrics and Gynecology at our hospital. The study was approved by local ethics committee of University of Health Sciences, Adana Numune Training and Research Hospital with the number of 7/113. Informed consent for review of records was deemed unnecessary in view of the retrospective nature of the study.

Placenta previa and PAS were diagnosed by color flow Doppler (trans-abdominally and trans-vaginally with Toshiba Xario machine (Shimoishigami, Otawara-shi, Tochigi 324-8550, Japan) equipped with a 2.8-7 megahertz $(\mathrm{MHz})$ transducer in all patients. Loss of normal hypoechoic retro-placental zone, thinner retro-placental myometrial thickness of $1 \mathrm{~mm}$, presence of multiple vascular lacunas (Swiss-cheese appearance) or turbulent blood flow through lacune, increased sub-placental vascularity and presence of vessels bridging from placenta to uterine magrin were used for diagnosis [4]. Moreover extension of villi into myometrium, serosa, or bladder and abnormalities of uterine serosa and bladder interface (such as interruption, thickening, irregularity of line and increased vascularity) were also confirmed by doppler ultrasound for the accurate diagnosis.

All demographic and obstetric information regarding age, smoking, parity, gestational week at delivery, pasthistory of cesarean section and presence of placenta previa were retrieved from the patients' data files. Length of hospital stay before and after operation, perioperative complications, comorbidities, preoperative and postoperative hemoglobin values were collected. Localization of placenta, maternal blood group, number of erythrocyte and/or fresh frozen plasma transfusions were all recorded from the patients files. All transfusions were considered by expert team (surgeons and anesthesiologists) upon on maternal hemodynamic status in line with the recommendations. Fetal weight and sex, apgar scores, admission to intensive care unit as well as perinatal outcomes were also noted.

Our inclusion criteria were patients diagnosed with placenta previa concomitant PAS between the ages of 18-45 years with complete pre- and post-natal data. Exclusion criteria included patients with coagulopathy, multiple gestation and pregnancies complicated with fetal chromosomal or congenital malformations.

Prior to 2016, routine surgical management for patients with strongly suspected placenta percreta was planned preterm cesarean hysterectomy. Since then, our management option has been modified to the local resection of the uterine site invaded by the placenta with the preservation of the uterus for selected patients. The surgical techniques used for the present study are presented in Table 1 .

General anesthesia was applied to all patients. The 
Table 1. Summary of local surgical resection tecnique of our clinic approach

1. Vertical midline insicion, uterus exteriorized and followed by vertical fundal incision
2. Fetal delivery
3. Placenta was clamped inside the uterus, leaving in place avoiding any attempt
4. Clamping (one for cervical and uterine arteries and one for ovarian ligaments) ligaments with specialized
vascular clamps (Figure 1)
5. Sharp and blunt dissection of the bladder, ligation of the perforating vessels between placenta and bladder
serosa (Figure 2)
6. Tracing the placental zone and mapping the expected resection area (Figure 2 )
7. Local (partial) resection of the uterine segment involving morbidly adherent placenta with the help of stretching
remained placenta from the fundal insicion (Figure 2$)$
8. Suturing the new uterine edges horizontally (Figure 2$)$
9. Applying a Latex Foley catheter $18 \mathrm{Fr} / \mathrm{Ch}$ (6.0 mm) inversely and filled with $80 \mathrm{ml}$ saline through the cervico-
vaginal canal for tamponading sutured new uterine zone
10. Closing the fundal incision vertically and removing the all clamps

appropriate crystalloid infusion, blood or products according to the clinical circumstances were administered during the resection of the uterine portion. A routinely oxytocin $30 \mathrm{UI}$ intravenous (i.v.) infusion and methylergobasine $0.2 \mathrm{mg}$ i.v. in single dose in selected patients if endicated were also applied. Internal iliac artery ligation was not performed in any cases presented in this study. An abdominal suction drain was placed to all patients.

\section{Surgical technique}

After the vertical midline incision, the uterus exteriorized and a vertical uterine fundal incision was performed. After fetal delivery, the placenta was clamped inside the uterus. Cervical and uterine arteries and ovarian ligaments were clamped with specialized vascular clamps (marked in Figure 1). After bladder dissection, perforating vessels between placenta and bladder serosa were ligated (marked in Figure 2).
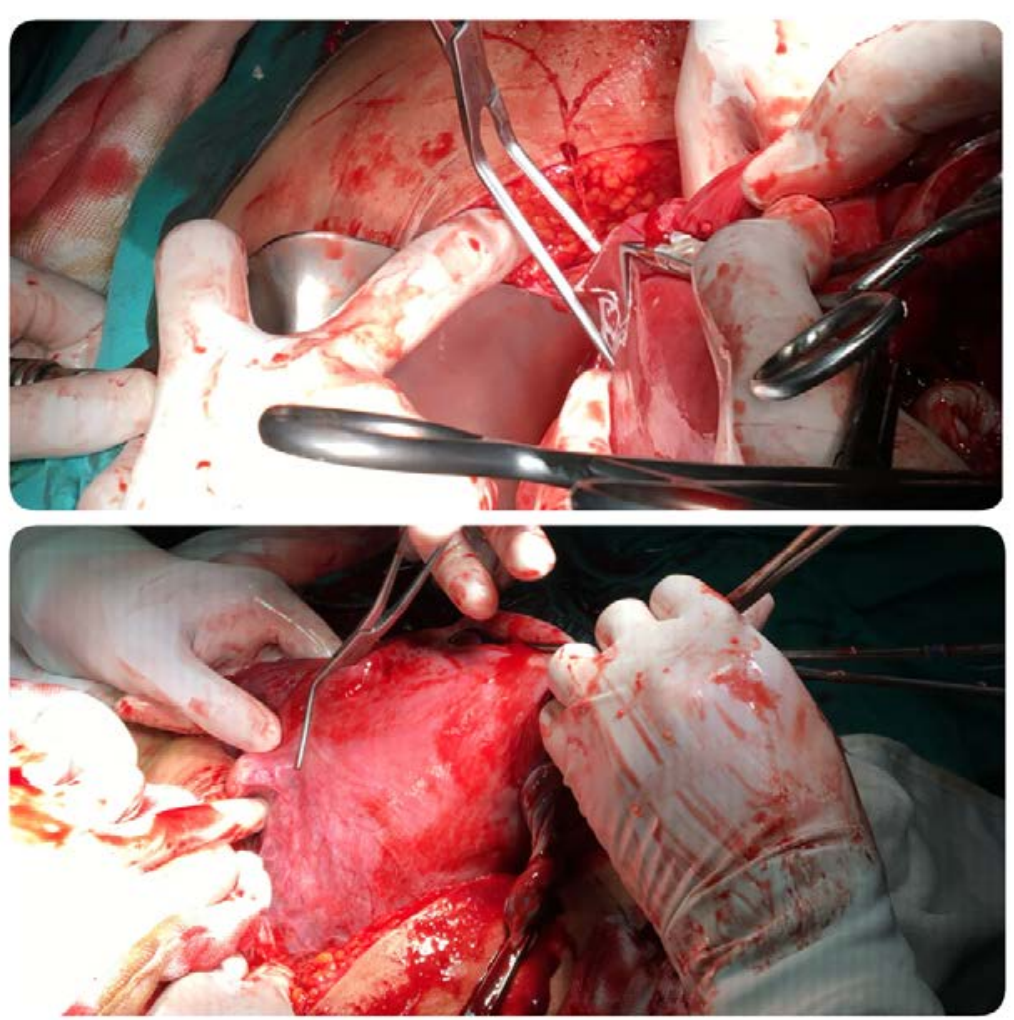

Figure1. Clamping of cervical and uterine arteries and ovarian ligaments (Marked with arrows in the figures) 


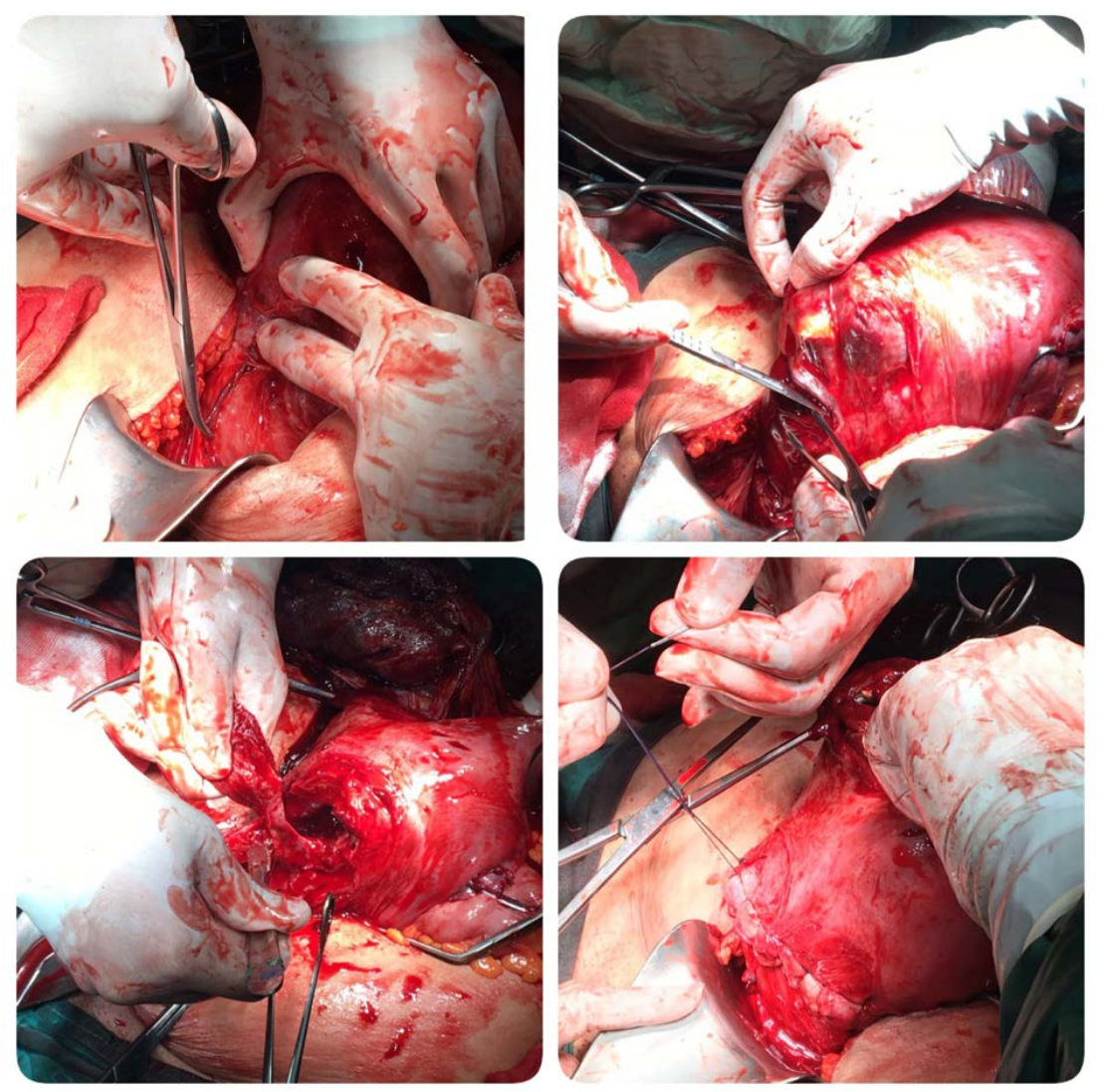

Figure 2. Perforating vessels between placenta and bladder serosawere ligated. After tracing the placental zone and mapping the expected resection area, local (partial) resection of the uterine segment involving morbidly adherent placenta were performed. New uterine edges were horizontally sutured. (Marked with arrows).

Placental zone and the expected resection area were mapped and traced. The uterine segment involving morbidly adherent placenta with the help of stretching remained placenta from the fundal incision was locally resected (marked in Figure 2). New uterine edges horizontally sutured. A latex Foley catheter $18 \mathrm{Fr} / \mathrm{Ch}$ $(6.0 \mathrm{~mm})$ filled with $80 \mathrm{ml}$ saline was applied inversely through the cervicovaginal canal for tamponading sutured new uterine zone. All clamps were removed and the fundal incision was closed vertically (Table 1).

\section{Statistical Analysis}

The clinical features of both groups were compared with the Statistical Package for Social Sciences (SPSS) for Windows, version 18.0 (SPSS Inc. IL, USA). Descriptive statistics were performed, including the description of quantitative variables, as the mean $\pm \mathrm{SD}$ and range, and description of qualitative variables as numbers and percentages. Normality of data distribution was tested with Kolmogorov-Smirnov test.

\section{RESULTS}

In this study, 11 cases of placenta previa concomitant PAS were identified from medical records. Local resection technique as uterus sparing method was performed in 10 patients. Bilateral tubal ligation was performed in 5 patients according to their preferences. Maternal demographic and surgical characteristics were summarized in Table 2. Two patients were admitted to our clinic with active vaginal bleeding and the surgery of others were performed in a planned preterm cesarean delivery (35-37 weeks). Regarding risk factors, all except one patient (Case no 9) had at least one previous cesarean section. There was no smoking history in mothers and one case had gestational diabetes and one had hypertension. Vertical skin incision under general anastesia were performed to all cases. The mean operative time was $99 \pm 30$ minutes. All of the cases had predominantly anterior placenta previa and were diagnosed with PAS by using preoperative color doppler ultrasound. The diagnosis was confirmed intraoperatively and send to 
Table 2. Demographic characteristics, maternal outcome and pathology of patients

\begin{tabular}{|c|c|c|c|c|c|c|c|c|c|c|c|}
\hline Case No. & 1 & 2 & 3 & 4 & 5 & 6 & 7 & 8 & 9 & 10 & 11 \\
\hline Age (years) & 27 & 42 & 30 & 44 & 33 & 28 & 30 & 25 & 21 & 34 & 28 \\
\hline $\mathbf{G} / \mathbf{P} / \mathbf{A}$ & 3.2 .2000 & 5.4 .2000 & 3.1 .2001 & 3.2 .2000 & 3.2 .2000 & 2.1 .2000 & 5.4 .2000 & 3.2 .2000 & 4.2 .2001 & 3.2 .2000 & 2.1 .2000 \\
\hline Risk factors & $\begin{array}{c}\text { PL } \\
\text { Previa } \\
\text { CSx2 }\end{array}$ & $\begin{array}{c}\text { PL. } \\
\text { Previa } \\
\text { CSx1 }\end{array}$ & $\begin{array}{c}\text { PL. } \\
\text { Previa } \\
\text { CSx1 }\end{array}$ & $\begin{array}{c}\text { PL. } \\
\text { Previa } \\
\text { CSx2 } \\
\text { GDM }\end{array}$ & $\begin{array}{c}\text { PL. } \\
\text { Previa } \\
\text { CSx2 } \\
\text { HT }\end{array}$ & $\begin{array}{c}\text { PL. } \\
\text { Previa } \\
\text { CSx1 }\end{array}$ & $\begin{array}{c}\text { PL. } \\
\text { Previa } \\
\text { CSx3 }\end{array}$ & $\begin{array}{c}\text { PL. } \\
\text { Previa } \\
\text { CSx2 }\end{array}$ & $\begin{array}{c}\text { PL. } \\
\text { Previa } \\
\text { CSx0 }\end{array}$ & $\begin{array}{c}\text { PL. } \\
\text { Previa } \\
\text { CSx2 }\end{array}$ & $\begin{array}{c}\text { PL. } \\
\text { Previa } \\
\text { CSx1 }\end{array}$ \\
\hline $\begin{array}{l}\text { Gestational age at } \\
\text { delivery (weeks) }\end{array}$ & 34 & 29 & 35 & 35 & 35 & 32 & 37 & 35 & 36 & 36 & 35 \\
\hline $\begin{array}{l}\text { Tubal ligation } \\
\text { (bilateral) }\end{array}$ & 0 & 1 & 0 & 1 & 1 & 0 & 1 & 0 & 0 & 1 & 0 \\
\hline Complications & none & none & none & $\begin{array}{l}\text { ICU } \\
\text { Bladder } \\
\text { injury }\end{array}$ & none & none & $\begin{array}{l}\text { ICU } \\
\text { Bladder } \\
\text { injury }\end{array}$ & none & none & none & C/SHys \\
\hline Preop Hb (g/dl) & 9.4 & 13.1 & 10.9 & 10.4 & 12.8 & 12 & 10.5 & 11.2 & 10.5 & 10.8 & 11 \\
\hline Postop Hb (g/dl) & 6.7 & 7.3 & 9.5 & 9.6 & 12.5 & 11.1 & 10.8 & 9.4 & 9.5 & 9.3 & 8.5 \\
\hline $\begin{array}{l}\text { Operative } \\
\text { duration (min) }\end{array}$ & 115 & 68 & 120 & 95 & 150 & 60 & 150 & 82 & 80 & 80 & 90 \\
\hline $\begin{array}{l}\text { Blood transfusion } \\
\mathrm{rbc} / \mathrm{ffp} / \mathrm{h}\end{array}$ & 2.2 .2001 & $1 / 0 / 2$ & 2.2 .2000 & 4.2 .2000 & 4.2 .2000 & $1 / 0 / 0$ & 3.1 .2000 & 1.1 .2000 & 1.1 .2000 & $2 / 0 / 0$ & 3.1 .2000 \\
\hline Early-op stay & 0 & 0 & 2 & 4 & 3 & 0 & 2 & 11 & 0 & 0 & 0 \\
\hline Post-op stay & 3 & 3 & 6 & 4 & 4 & 3 & 3 & 7 & 3 & 4 & 5 \\
\hline
\end{tabular}

pathological evaluation for gross and the histopathologic examination of the resected part. Regarding histopathological reports the largest resected area was $10 \times 6 \mathrm{~cm}$ and the minimum was $3 \times 3$ $\mathrm{cm}$. The mean age of the patients was $31 \pm 6.8$ years, ranged from 21 to 44 years. The mean gestational week at delivery was $34 \pm 2.2$, ranged from 29 to 37 weeks. Regarding intraoperative complications, two patients had intraoperative bladder injury and urinary catheter was applied with a period of 10 days for these patients. Postoperative hemorrhage occured in one case and a cesarean hysterectomy performed in a second operation. Two patients were transferred to intensive care unit (ICU) postoperatively and stayed 2 days until hemodynamically stabilizated. Before surgery, 4 units of packed red blood cells and fresh frozen plasma were prepared in case of emergency use for all patients. The mean preoperative and postoperative hemoglobin $(\mathrm{Hb})$ level was $11 \pm 1.1$ $\mathrm{g} / \mathrm{dL}, 9.2 \pm 1.7 \mathrm{~g} / \mathrm{dL}$, respectively. All patients received at least one unit of red blood cells intraoperatively (min: 1-max: 4). The mean received packed red blood

Table 3. Fetal - Neonatal characteristics and outcomes of patients

\begin{tabular}{lcccccccccccc}
\hline Case No. & $\mathbf{1}$ & $\mathbf{2}$ & $\mathbf{3}$ & $\mathbf{4}$ & $\mathbf{5}$ & $\mathbf{6}$ & $\mathbf{7}$ & $\mathbf{8}$ & $\mathbf{9}$ & $\mathbf{1 0}$ & $\mathbf{1 1}$ \\
\hline $\begin{array}{l}\text { Gender } \\
\text { Presentation }\end{array}$ & Male & Male & Female & Male & Female & Female & Female & Male & Female & Male & Female \\
$\begin{array}{l}\text { Birth weight } \\
\text { (g) }\end{array}$ & 2150 & 1310 & 2600 & 2750 & 2458 & 1700 & 3100 & 2700 & 2900 & 2850 & 2760 \\
$\begin{array}{l}\text { Head } \\
\text { circumference }\end{array}$ & 32 & 29 & 32 & 33 & 32 & 30 & 34 & 34 & 35 & 33 & 32 \\
(cm) & & & & & & & & & & & & \\
Height (cm) & 45 & 40 & 43 & 47 & 47 & 42 & 49 & 49 & 48 & 48 & 47 \\
$\begin{array}{l}\text { Apgar 1st } \\
\text { minute }\end{array}$ & 9 & 7 & 6 & 7 & 7 & 7 & 7 & 9 & 7 & 7 & 6 \\
$\begin{array}{l}\text { Apgar 5th } \\
\text { minute }\end{array}$ & 10 & 9 & 8 & 8 & 9 & 9 & 9 & 10 & 9 & 9 & 8 \\
\hline
\end{tabular}


cells was $2.3 \pm 1.0$ units. A routinely abdominal drain were placed to all patients and mean removal day was one day. The mean lenght of postoperative hospital stay was $4.5 \pm 1.4$ days. There was no late complications regarding coagulopathy and enfection. No maternal mortality was observed.

Regarding follow-up controls (4 of patients lost follow-up) had no complaint about anormal uterine bleeding or abnormal menstruation. Up to the time this research was conducted no patients had a new pregnancy after this operation.

Fetal and neonatal outcomes were summarized in Table 3 . There was only 2 cases with $<7$ Apgar scores in the first minutes. All Apgar scores in 5th minutes were above 7 . There were 6 non-vertex presentation. Since prematurity, 2 of babies were transferred to neonatal ICU. No neonatal death was observed.

\section{DISCUSSION}

The present study has shown that local resection tecnique is a safe and effective method in treatment of anterior PAS disorders. The surgical results of 11 cases with PAS were presented in the present study, including maternal and fetal outcomes. Although it is not often possible to perform this tecnique to all patients, local resection should be reserved for the women with strong fertility desire or uterine sparement. PAS is a life-threatening condition causing maternal mortality and morbidity, and is no longer a rare obstetric situation. The incidence of PAS has increased from approximately one case per 1000 deliveries in the 1980s to three per 1000 deliveries in the past decade $[1,16]$. As the number of caesarean section increases, the more number of morbidity invasive placenta will be encountered. Therefore, new uterine sparing methods are being suggested in the literature but conclusions about the superiority of any method still could not be drawn.

The main risk factor for placenta accreta is placenta previa $[1,10]$. Repeated caesarean sections and multiple uterine $\mathrm{D} / \mathrm{C}$ are also important risks factors, due to myometrial damage. In the present study there was only one patient without any ceseraen history, but had a D/C history. Clinicians should be careful regarding placental invasion abnormalities even in patients with placenta previa without any cesarean history.

Lower uterine segment, a highly vascularized structure, is perfused by the cervical artery, the inferior vesical artery and by the upper, middle and lower vaginal arteries [17]. Regarding this anastomotic compensation internal iliac artery ligation or occlusion is insufficent for PAS. Also, bilateral internal iliac artery ligation is skillful and an unsuitable procedure with difficulties in observation. Unlike other situations (myoma uteri), due to fragile tissues of adhesive plasenta, tourniquet of servix maynot be suitable. In this local resection tecnique we used specialized vascular clamps, one for servical and uterine arteries and one for ovarian ligaments. Therefore, we blocked the anastomotic compensation and uterine blood flow. We prefered this procedure instead of internal iliac artery ligation or balon catheter occlusion.

Palacios et al. [10] first described en bloc resection of myometrium in patients with placenta percreta in 2004. They ligatured bilateral uterine arteries and local bleeding was controlled with additive sutures $\mathrm{s}$ electively including the anterior and posterior cervical and vaginal arteries. After resection they covered primarly sutured area with absorbable mesh and fibrine glue. Uterine conservation was managed in 50 (74\%) of the 68 women.

Chandaran et al. [11] described triple $\mathrm{P}$ tecnique in 2006 in a case series of 4 women with anterior placenta percreta. According to this procedure firstly horizontal incision was made 2 finger breadths above the placental edge. Secondly, preoperatively placed intraarterial balloon catheters were inflated after delivery. Thirdly en bloc myometrial excision was made and new zone was repaired [11]. The potential benefit of this procedure was to minimize the surgical dissection while removing the adhesive placenta in appropriately selected patients. In our study we performed vertical fundal incision for fetal delivery to prevent high blood loss.

Shabana et al. [12] reported modified surgical approach in the form of stepwise cesarean section in 71 patients with placenta percreta. They also made horizontal uterine incision for fetal birth and after bilateral internal iliac artery ligation, en bloc resection of adhesive myometrial region was performed. They emphasized conservative rather than radical surgical aspects.

Karaman et al. [15] also reported that local 
resection of percreta site is an effective, safe, and fertility preserving approach. They presented 12 cases with placenta percreta and 4 of these underwent hysterectomy. One of our cases was underwent second laparotomy because of excessive bleeding through abdominal suction drain. The greatest difference between two techniques (local resection) was internal iliac artery ligation. In our study, we performed pelvic devascularization with a more simple way of ligation by vascular clamps in a short period of time. Similar to our study, the presence of placenta previa was predominating anteriorly in most of their cases. In patients with placenta previa regarding lateraly and posterior predominating localization, both diagnosis and treatment are difficult. The preservation of uterus remains challenging with adhesive parts to the neighboring organs. In those patients we recommend cesarean hysterectomy instead of local resection.

Since biopsy is obtained in an area without invasion or with a degree of minor penetration, the histopathological study of invasive placenta does not always constitute a diagnostic "gold standard" [10]. For this reason, a mismatch between histology and the surgical finding may occur in some cases. Therefore, we prefered todefine placenta accreta according to its clinical-surgical characteristics in this study.

In recent studies, fetal outcomes of placenta previa were conflicting [18, 19]. Rosenberg et al. [18] revealed an association between placenta previa and intrauterine growth retardation. Yeniel et al. [19] explored only neonatal outcomes and did not find an association between either fetal growth restriction or fetal demise with placenta previa. In our study, there were only two cases with $<7$ Apgar scores in the first minutes. All Apgar scores in 5th minutes were above 7. General anesthesia may affect may affect Apgar scores in the first minutes. There were no intrauterine growth retardation in our study.

The major strength of our local resection tecnique is its easy procedure with daily used equipment leading safe and effective results. Moreover, this is probably the first study that fully investigates the resection procedure on fetal outcomes in patients with PAS.

\section{Limitations}

The main limitation of the present study was its retrospective design. Another potential limitation was that we could not have ascertained all cases because of absent data.

\section{CONCLUSION}

Local resection tecnique is easy to perform and does not require special equipment or skills. This rapid procedure could be the management approach of choice not only for patients who want to retain their uterus and fertility, but also for patients with invasive placenta who are at increased risk of surgical morbidity. Nevertheless, the present results should be confirmed with further randomized prospective trials.

\section{Conflict of interest}

The authors disclosed no conflict of interest during the preparation or publication of this manuscript.

\section{Financing}

The authors disclosed that they did not receive any grant during conduction or writing of this study.

\section{REFERENCES}

[1] Wu S, Kocherginsky M, Hibbard JU. Abnormal placentation: twentyyear analysis. Am J Obstet Gynecol 2005;192:1458-61.

[2] Fox KA, Shamshirsaz AA, Carusi D, Secord AA, Lee P, Turan OM, et al. Conservative management of morbidly adherent placenta: expert review.Am J Obstet Gynecol 2015;213:755-60.

[3] Kutuk MS, Ak M, Ozgun MT. Leaving the placenta in situ versus conservative and radical surgery in the treatment of placenta accreta spectrum disorders. Int J Gynaecol Obstet 2018;140:338-44.

[4] Silver RM, Fox KA, Barton JR, Abuhamad AZ, Simhan H, Huls CK, et al. Center of excellence for placenta accreta.Am J Obstet Gynecol 2015;212:561-8.

[5] Imudia AN, Awonuga AO, Dbouk T, Kumar S, Cordoba MI, Diamond MP, et al. Incidence, trends, risk factors, indications for, and complications associated with cesarean hysterectomy: a 17-year experiencefrom a single institution. Arch Gynecol Obstet 2009;280:61923.

[6] Fitzpatrick KE, Sellers S, Spark P, Kurinczuk JJ, Brocklehurst P, Knight M. The management and outcomes of placenta accreta, increta, and percreta in the UK: a population-based descriptive study. BJOG 2014;121:62-70.

[7] Committee on Obstetric Practice. Committee opinion no. 529: placenta accreta. Obstet Gynecol 2012;120:207-11.

[8] Jeremiah M. Fecundity, Barrenness and the importance of motherhood in two Nigerian plays. Int J Humanit Soc Sci 2014;4:21321.

[9] Clausen C, Lonn L, Langhoff-Roos J. Management of placenta percreta: a review of published cases. Acta Obstet Gynecol Scand 2014;93:138-43.

[10] Palacios Jaraquemada JM, Pesaresi M, Nassif JC, Hermosid S. 
Anterior placenta percreta: surgical approach, hemostasis and uterine repair. Acta Obstet Gynecol Scand 2004;83:738-44.

[11] Chandraharan E, Rao S, Belli AM, Arulkumaran S. The Triple-P procedure as a conservative surgical alternative to peripartum hysterectomy for placenta percreta. Int J Gynaecol Obstet 2012;117:1914.

[12] Shabana A, Fawzy M, Refaie W. Conservative management ofplacenta percreta: a stepwise approach. Arch Gynecol Obstet 2015;291:993-8.

[13] Lin K, Qin J, Xu K, Hu W, Lin J. Methotrexate management for placenta accreta: a prospective study. Arch Gynecol Obstet 2015;291:1259-64.

[14] Hequet D, Morel O, Soyer P, Gayat E, Malartic C, Barranger E. Delayed hysteroscopic resection of retained tissues and uterine conservation after conservative treatment for placenta accreta. Aust $\mathrm{N}$ Z J Obstet Gynaecol 2013;53:580-3.

[15] Karaman E, Kolusarı A, Çetin O, Çim N, Alkış İ, Yıldızhan R, et al. Local resection may be a strong alternative to cesarean hysterectomy in conservative surgical management of placenta percreta: experiences from a tertiary hospital. J Matern Fetal Neonatal Med 2017;30:947-52. [16] Publications Committee, Society for Maternal-Fetal Medicine, Belfort MA. Placenta accreta. Am J Obstet Gynecol 2010;203:430-9.

[17] Palacios Jaraquemada JM, Garcia Monaco R, Barbosa NE, Ferle $\mathrm{L}$, Iriarte $\mathrm{H}$, Conesa HA. Lower uterine blood supply: extrauterineanastomotic system and its application in the surgical devascularization techniques. Acta Obstet Gynecol Scand 2007;86:22834.

[18] Rosenberg T, Pariente G, Sergienko R, Wiznitzer A, Sheiner E. Critical analysisof risk factors and outcome of placenta previa. Arch Gynecol Obstet 2011;284:47-51.

[19] Yeniel AO, Ergenoglu AM, Itil IM, Askar N, Meseri R. Effect of placenta previaon fetal growth restriction and stillbirth. Arch Gynecol Obstet 2012;286:295-8. 